\title{
STUDI VARIASI JENIS MATERIAL TALI PADA MODIFIKASI ALAT PENGUKURAN TORSI POMPA SENTRIFUGAL
}

\author{
Taufik Afandi ${ }^{1}$, Edi Widodo ${ }^{2}$, Prantasi $\mathrm{HT}^{4}$, Iswanto $^{4}$ \\ ${ }^{1,4}$ Program Studi Teknik Mesin, Universitas Muhammadiyah Sidoarjo \\ ipangvia11@gmail.com¹,ediwidodo@umsida.ac.id²
}

\begin{abstract}
Abstrak - Pengukuran torsi pompa sentrifugal di laboratorium fluida Universitas Muhammadiyah Sidoarjo memanfaatkan tegangan tali yang dihubungkan dengan motor listrik penggerak. Fokus penelitian ini untuk membandingkan jenis material dan ukuran tali yang sesuai untuk meminimalisir kerugian gaya yang terdapat pada kawat serta perhitungan perbandingan nilai berbagai variasi jenis material. Metode eksperimen dilakukan dalam membandingkan tali yang dipakai. Dari pengujian tarik yang telah dilakukan, nilai UTS (Ultimate Tensille Stress) tertinggi di dapatkan pada spesimen tali polypropylene monofilament dengan nilai tegangan tarik 602, 17 kgf dengan elongation 382,14\%. Data nilai perhitungan stress tertinggi di peroleh oleh specimen tali Polypropylene monofilament dengan nilai $738,85 \mathbf{~} \mathbf{g f} / \mathbf{c m}^{2}$ pada elongation ke $360 \%$. Nilai modulus elastisitas tertinggi diperoleh tali Nylon sebesar 4,564 $\mathbf{k g f} / \mathbf{c m}^{2}$. Ini menunjukan bahwa modulus elastisitas tali nylon memiliki nilai modulus elastisitas paling tinggi di antara specimen yang lain.
\end{abstract}

Kata Kunci : Uji torsi pompa sentrifugal, modifikasi alat uji.

Abstract- Measurement of centrifugal pump torque at the University of Muhammadiyah Sidoarjo fluid laboratory utilizes a rope tension connected to an electric motor. The focus of this research is to analyze variations in the type of rope material and size as a link for measuring the force on a centrifugal pump, namely to find out the type of material and the size of the rope that is suitable to minimize the loss of force contained in the wire. To find out the type of calculation and comparison of the values for various types of material. From the tensile test that has been done, the highest UTS (Ultimate Tensille Stress) value was obtained in a polypropylene monofilament rope specimen with a stress value of $602.17 \mathrm{kgf}$ with $382.14 \%$ elongation. The highest stress calculation value data was obtained by the Polypropylene monofilament rope specimen with a value of $738,85 \mathrm{kgf} / \mathrm{cm}^{2}$ at elongation to $360 \%$. The highest modulus of elasticity obtained by Nylon rope was $4,564 \mathrm{kgf} / \mathrm{cm}^{2}$. This shows that the elastic modulus of nylon rope has the highest modulus of elasticity among other specimens..

Keywords - centrifugal pump torque test, modification of measuring instruments .

\section{PENDAHULUAN}

Pompa air adalah alat untuk mentransportasikasn fluida cair, alat ini sudah sangat umum dipakai dan sering dijumpai pada kehidupan sehari - hari. Mempunyai manfaat yang cukup baik dalam menyelesaikan persoalan dalam kehidupan sehari - hari yang berkaitan dengan pemindahan fluida cair.

Secara teori pompa merupakan suatu alat untuk memberikan suatu energi mekanis terhadap cairan pada pompa, densitas fluida besar dan konstan. Untuk pemilihan jenis pompa yang dipakai didasari dari nilai ekonomis dan jarak fluida yang akan dipindahkan. Dimana prinsip kerjanya sendiri yaitu mengubah suatu energi mekanik menjadi potensial fluida [1][2].[3]

Pompa memiliki prinsip kerja membuat tekanan rendah pada isap, sehingga mengakibatkan terhisapnya fluida masuk dan keluar dengan tekanan yang lebih tinggi pada sisi keluar atau sisi tekan dengan menggunakan semua bagian bagian elemen penggerak pompa seperti plunger atau piston, impeller[4]. Sumber energy diperoleh dari luar yaitu motor bakar atau motor listrik agar pompa dapat bekerja [5].[6]
Dinamometer adalah suatu alat yang digunakan untuk mengukur daya atau tenaga yang dihasilkan atau dikeluarkan oleh sebuah mesin. Selain itu, dynamometer juga biasa digunakan sebagai pengukur torsi atau putaran mesin (rpm) di mana daya atau tenaga yang dihasilkan dari suatu alat yang berputar atau mesin dapat dihitung berat suatu benda, berat benda yang di maksud adalah gaya berat atau massa dikali dengan percepatan gravitasi, bukan masa itu sendiri.

Penelitian sebelumnya, dinamometer digunakan untuk mengukur gaya torsi pompa sentrifugal.[7][8] Pada penelitian ini dilakukan modifikasi menggunakan sebuah kabel sebagai penghubung dari pengait pada dinamometer ke pompa sentrifugal. Kabel tersebut berfungsi untuk menghantarkan gaya torsi pompa dan dihubungkan dengan dinamometer. 


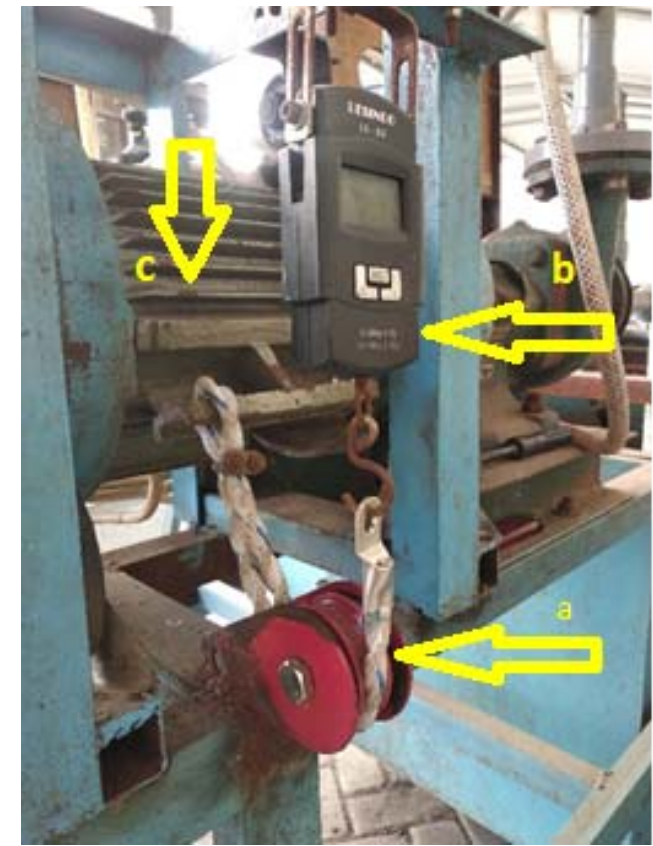

Gambar 1 Aplikasi tali pada pengukur torsi pompa sentrifugal (a) Tali penghubung, (b) dynamometer, (c) pompa sentrifugal

\section{METODE}

Penelitian membandingkan hasil pengujian tarik pada tali polypropylene monofilament, tali polypropylene multi filament, tali nylon dan tali tampar. Berikut diagram alir penelitian yang dilakukan:

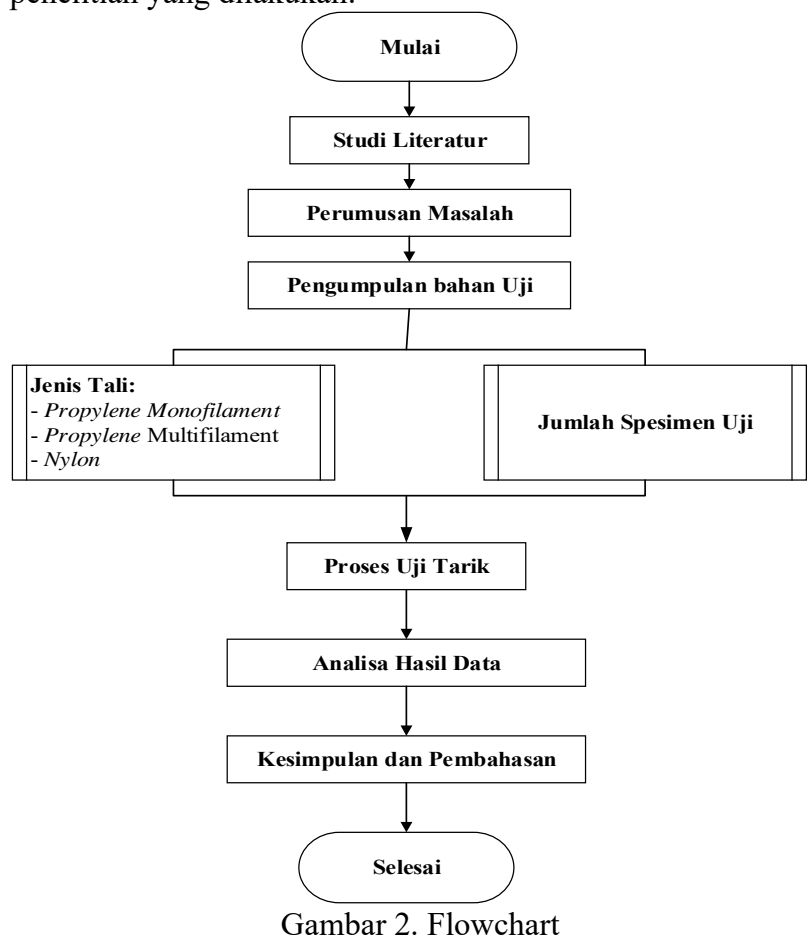

Parameter Penelitian

Adapun parameter dalam penelitian ini yaitu:

a) Penelitian difokuskan pada pengujian tarik dan lakukan pengujian dengan empat buah specimen yaitu tali Polypropylene monofilament, tali polypropylene multifilament, tali nylon dan tali tampar untuk membandingkan kekuatan ke empat tali tersebut.

b) Pada penelitian ini digunakan mesin merek Zwick/Roell dengan tipe Z005.

c) Untuk jenis specimen yang akan diuji pada proses penelitian ini, dapat dilihat pada tabel 1 .

Tabel 1 Tabel Spesifikasi Sampel

\begin{tabular}{clcc}
\hline \multirow{2}{*}{ No. } & \multicolumn{2}{c}{ Jenis Bahan } & \multicolumn{2}{c}{ Ukuran } \\
\cline { 3 - 4 } & & Panjang & Diameter \\
\hline 1. & $\begin{array}{l}\text { Tali Propylene } \\
\text { Monofilament } \\
\text { Tali Propylene }\end{array}$ & $100 \mathrm{~cm}$ & $1 \mathrm{~cm}$ \\
2. & $\begin{array}{l}\text { Multifilament } \\
\text { 3. }\end{array}$ & $100 \mathrm{~cm}$ & $1 \mathrm{~cm}$ \\
T. & Tali Nylon & $100 \mathrm{~cm}$ & $1 \mathrm{~cm}$ \\
\hline
\end{tabular}

d) Data yang diperoleh kemudian akan dilakukan proses perhitungan untuk mendapatkan nilai yang sebenarnya dari suatu pengujian, proses perhitungan dilakukan dengan menggunakan persamaan :

\section{Proses Perhitungan}

Tegangan

$$
\begin{aligned}
& \text { Tegangan } \sigma=\frac{\mathrm{F}}{A_{0}}=\ldots \ldots(k g f / \\
& \left.\mathrm{cm}^{2}\right) \text {. } \\
& \text { - } \mathrm{A}=\text { Luas Penampang }\left(\mathrm{cm}^{2}\right) \\
& \text { - } \mathrm{r} \quad=\text { Jari }- \text { jari }(\mathrm{cm}) \\
& \text { - } \mathrm{F} \quad=\text { Beban Pada pengujian }(k g f) \\
& \text { - } \epsilon \quad=\text { Regangan (\%) } \\
& \text { - } \sigma=\text { Stress }\left(\mathrm{kgf} / \mathrm{cm}^{2}\right)
\end{aligned}
$$

Di mana:

\section{Modulus Elastisitas}

$$
\begin{array}{r}
Y=\frac{\text { Tegangan }}{\text { Regangan }}=\frac{\sigma}{\varepsilon}= \\
\frac{F / A}{\Delta \ell / \ell_{0}} \ldots \ldots \ldots \ldots \ldots \ldots \ldots \ldots \ldots \ldots \ldots \ldots \ldots \ldots \ldots \ldots \ldots \ldots
\end{array}
$$

Dimana;

$$
\begin{array}{ll}
\mathrm{Y} & =\text { Modulus young } \\
\sigma & =\text { Tegangan Tarik } \\
\varepsilon & =\text { Regangan } \\
\mathrm{F} & =\text { Gaya }(\mathrm{N}) \\
\mathrm{A} & =\text { Luas permukaan }\left(\mathrm{m}^{2}\right) \\
\ell_{0} & =\text { panjang awal } \\
\Delta \ell & =\text { perubahan panjang }(\mathrm{m})
\end{array}
$$

Bagian ini memuat penjelasan tentang metode yang digunakan untuk menjawab atau memecahkan permasalahan/penelitian yang diajukan. Disini bisa dalam 
bentuk studi literatur, simulasi numerik, atau dalam bentuk eksperimen.

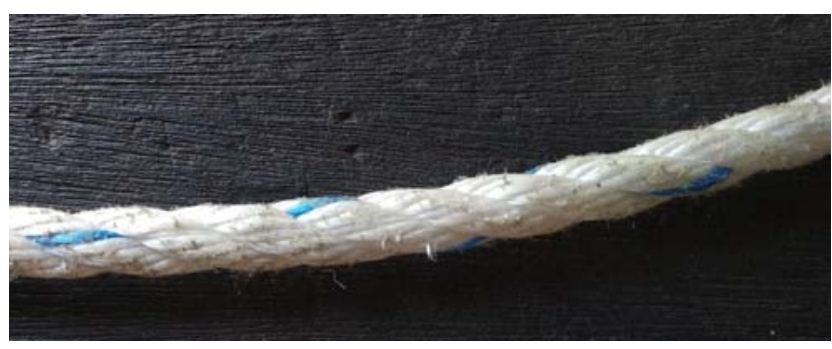

Gambar 3 Tali Polypropylene Monofilament

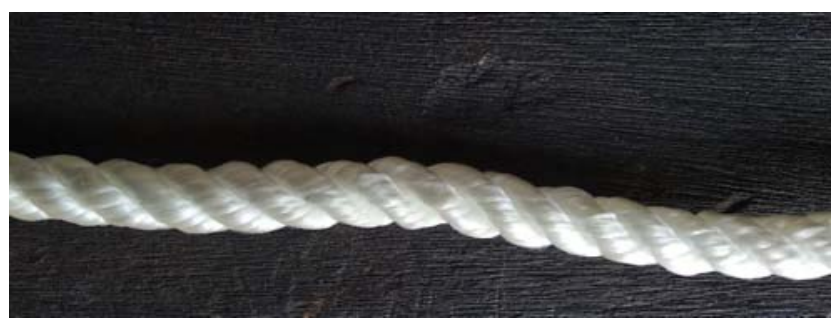

Gambar 4 Tali Polypropylene Multifilamet

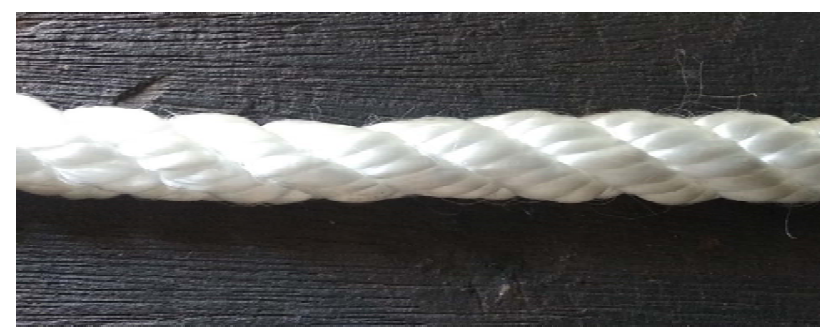

Gambar 5 Tali Nylon

\section{HASIL DAN DISKUSI}

\section{Data Hasil Pengamatan}

Dari hasil proses pengujian tarik dari sebuah bahan atau specimen yang berupa tali polypropylene monofilament, tali polypropylene multi filament, tali nylon dan tali tampar maka didapatkan hasil pengamatan lapangan yang mana data tersebut disajikan di dalam sub bab di bawah ini.

Tali Polypropylene Monofilament

Specimen pertama berupa tali polypropylene monofilament, didapatkan data pengujian tarik pada tabel 2 pemilihan material dengan merujuk penelitian sebelumnya. [9]:
Tabel 2 Data Pengujian Tali PP Monofilament

\begin{tabular}{ccc}
\hline \multirow{2}{*}{ Elongation $\%$} & \multicolumn{2}{c}{ Gaya Tarik } \\
\cline { 2 - 3 } 20 & $f_{1}(k g f)$ & $f_{2}(k g f)$ \\
40 & 20 & 20 \\
60 & 50 & 50 \\
80 & 80 & 80 \\
100 & 120 & 120 \\
120 & 110 & 113 \\
140 & 135 & 140 \\
160 & 135 & 135 \\
180 & 160 & 180 \\
200 & 170 & 210 \\
220 & 202 & 240 \\
240 & 245 & 280 \\
260 & 298 & 325 \\
280 & 340 & 380 \\
300 & 413 & 435 \\
320 & 480 & 485 \\
340 & 549 & 510 \\
360 & 580 & 200 \\
380 & 549 & 280 \\
\hline & &
\end{tabular}

\section{Tali Polypropylene Multifilament}

Specimen ke dua berupa tali polypropylene multifilament, yang mana didapat kan data pengujian tarik pada tabel 3. Pemilihan material ini berdasar pada penelitian sebelumnya.[10]

Tabel 3 Data Pengujian Tali PP Multifilament

\begin{tabular}{cccc}
\hline \multirow{2}{*}{ Elongation \% } & \multicolumn{3}{c}{ Gaya Tarik } \\
\cline { 2 - 4 } & $f_{1}(k g f)$ & $f_{2}(k g f)$ & $f_{3}(k g f)$ \\
\hline 20 & 20 & 20 & 20 \\
40 & 47 & 70 & 40 \\
60 & 75 & 95 & 60 \\
80 & 95 & 80 & 95 \\
100 & 120 & 135 & 99 \\
120 & 190 & 160 & 160 \\
140 & 225 & 210 & 215 \\
160 & 275 & 260 & 280 \\
180 & 340 & 285 & 352 \\
200 & 360 & 320 & 408 \\
220 & & 200 & 380 \\
\hline
\end{tabular}

\section{Tali Nylon}

Specimen ketiga berupa tali Nylon, yang mana didapatkan data hasil pengujian tarik pada tabel 4. Pemilihan material ini merujuk pada penelitian sebelumnya. [11]: 
Tabel 4 Data Pengujian Tali Nylon

\begin{tabular}{cccc}
\hline \multirow{2}{*}{ Elongation \% } & \multicolumn{3}{c}{ Gaya Tarik } \\
\cline { 2 - 4 } & $f_{1}(\mathrm{kgf})$ & $f_{2}(\mathrm{kgf})$ & $f_{3}(\mathrm{kgf})$ \\
\hline 20 & 45 & 23 & 40 \\
40 & 80 & 30 & 90 \\
60 & 60 & 65 & 80 \\
80 & 145 & 75 & 140 \\
100 & 220 & 124 & 192 \\
120 & 275 & 205 & 264 \\
140 & 310 & 285 & 335 \\
160 & & 375 & 250 \\
180 & & 315 & \\
200 & & & \\
\hline
\end{tabular}

\section{Tali Tampar}

Spesimen ke empat berupa tali tampar, yang mana didapatkan hasil data pengujian tarik sebagaimana table 5 . Pemilihan spesimen tampar merujuk pada penelitian sebelumnya.[12]

Tabel 5 Data Pengujian Tali Tampar

\begin{tabular}{ccc}
\hline \multirow{2}{*}{ Elongation \% } & \multicolumn{2}{c}{ Gaya tarik } \\
\cline { 2 - 3 } & $f_{1}(\mathrm{kgf})$ & $f_{2}(\mathrm{kgf})$ \\
\hline 20 & 2,5 & 20 \\
40 & 10 & 40 \\
60 & 12 & 60 \\
80 & 17,5 & 80 \\
100 & 24 & 100 \\
120 & 28 & 120 \\
140 & 36 & 140 \\
160 & 41 & 160 \\
180 & 46 & 180 \\
200 & 52 & 200 \\
220 & 56 & 220 \\
\hline
\end{tabular}

\section{Proses Pengolahan Data}

Pada proses ini akan dilakukan suatu perhitungan data untuk mendapatkan nilai tegangan atau stress yang akan di gunakan untuk menghasilkan grafik dengan elongation sebagai sumbu $\mathrm{x}$ dan stress sebagai sumbu y, yang mana nanti akan digunakan untuk menentukan modulus elastisitas pada masingmasing ke empat specimen pengujian di atas. Proses Perhitungan terkait pengujian Tarik sebagaimana berikut :

\section{Perhitungan Tali (PP Monofilament)}

Rumus dasar:

$$
\sigma=\frac{\sigma}{A_{0}}=\ldots \ldots . .\left(\mathrm{kgf} / \mathrm{cm}^{2}\right)
$$

Keterangan :

$$
\begin{array}{lll}
- & \mathrm{A} & =\text { Luas Penampang }\left(\mathrm{cm}^{2}\right) \\
- & \mathrm{r} & =\text { Jari }- \text { jari }(\mathrm{cm}) \\
- & \mathrm{F} & =\text { Beban Pada pengujian }(\mathrm{kgf}) \\
- & \epsilon & =\text { Regangan }(\%) \\
- & \sigma & =\text { Stress }\left(\mathrm{kgf} / \mathrm{cm}^{2}\right)
\end{array}
$$

- Perhitungan luas penampang

$$
\begin{aligned}
A & =\pi r^{2} \\
& =3,14 \times 5^{2} \\
& =78,5 \mathrm{~mm}^{2}
\end{aligned}
$$

$$
=0,785 \mathrm{~cm}^{2}
$$

- Perhitungan gaya tarik $(\sigma)$ percobaan ke 1 tiap $\%$ elongation

Diketahui :

$$
\begin{array}{lll}
\text { - } & \text { A } & : 0,785 \mathrm{~cm}^{2} \\
\text { - } & \sigma \text { tiap } \epsilon \% & : \ldots \ldots . \mathrm{kg}
\end{array}
$$

Elongation ke $20 \%$

$$
\sigma=\frac{20}{0,785}=25,48
$$

$>$ Elongation ke $40 \%$

$$
\sigma=\frac{25}{0,785}=31,85
$$

elongation ke $60 \%$

$$
\sigma \quad=\frac{50}{0,785}=63,69
$$

$>$ elongation $\mathrm{ke} 80 \%$

\begin{tabular}{|c|c|c|c|c|c|}
\hline \multirow{2}{*}{$\begin{array}{c}\text { Elongation } \\
(\%)\end{array}$} & $\begin{array}{r}\mathrm{D} \\
\text { Pen } \\
(k\end{array}$ & $\begin{array}{l}\text { ta } \\
\text { ajian } \\
\text { f) }\end{array}$ & $\begin{array}{c}A_{0} \\
\left(\mathrm{~cm}^{2}\right)\end{array}$ & \multicolumn{2}{|c|}{$\begin{array}{l}\text { Hasil }(k g f / \\
\left.\mathrm{cm}^{2}\right)\end{array}$} \\
\hline & $f 1$ & $f 2$ & & $\sigma 1$ & $\sigma 2$ \\
\hline 20 & 20 & 20 & 0,785 & 25,48 & 25,48 \\
\hline 40 & 25 & 25 & 0,785 & 31,85 & 31,85 \\
\hline 60 & 50 & 50 & 0,785 & 63,69 & 63,69 \\
\hline 80 & 80 & 80 & 0,785 & 101,91 & 101,91 \\
\hline 100 & 120 & 120 & 0,785 & 152,87 & 152,87 \\
\hline 120 & 110 & 113 & 0,785 & 140,13 & 143,95 \\
\hline 140 & 135 & 140 & 0,785 & 171,97 & 178,34 \\
\hline 160 & 135 & 135 & 0,785 & 171,97 & 171,97 \\
\hline 180 & 160 & 180 & 0,785 & 203,82 & 229,30 \\
\hline 200 & 170 & 210 & 0,785 & 216,56 & 267,52 \\
\hline 220 & 202 & 240 & 0,785 & 257,32 & 305,73 \\
\hline 240 & 245 & 280 & 0,785 & 312,10 & 356,69 \\
\hline 260 & 298 & 325 & 0,785 & 379,62 & 414,01 \\
\hline 280 & 340 & 380 & 0,785 & 433,12 & 484,08 \\
\hline 300 & 413 & 435 & 0,785 & 526,11 & 554,14 \\
\hline 320 & 480 & 485 & 0,785 & 611,46 & 617,83 \\
\hline 340 & 549 & 510 & 0,785 & 699,36 & 649,68 \\
\hline 360 & 580 & 200 & 0,785 & 738,85 & 254,78 \\
\hline 380 & 549 & 280 & 0,785 & 699,36 & 356,69 \\
\hline
\end{tabular}

$$
\sigma \quad=\frac{80}{0,785}=101,91
$$

elongation ke $100 \%$

$$
\sigma \quad=\frac{120}{0,785}=152,87
$$

demikian seterusnya untuk perhitungan ketiga spesimen berikutnya.

\section{Data Hasil Perhitungan}

Perhitungan dilakukan untuk menentukan nilai gaya tarik $(\sigma)$ pada tiap elongation pada tiap specimen. Hasil perhitungan tali PP Monofilament tersebut telah tersaji dalam tabel 6. Untuk perhitungan 3 spesimen berikutnya (PP multifilamen, nylon dan tali tampar) menggunakan metode perhitungan yang sama dan didapatkan hasil perhitungan sebagaimana tabel 6 .

Tabel 6 Perhitungan dan Grafik Tali PP Monofilament 


\section{Grafik Tegangan - Regangan Hasil Perhitungan}

Dari data perhitungan yang merupakan data dari spesimen tali PP monofilament, tali PP multifilament, tali nylon, serta tali tampar, ditampilkan grafik untuk menentukan nilai modulus elastisitas (E) sebagaimana grafik berikut:

\section{Grafik Tegangan - Regangan Tali PP Monofilament}

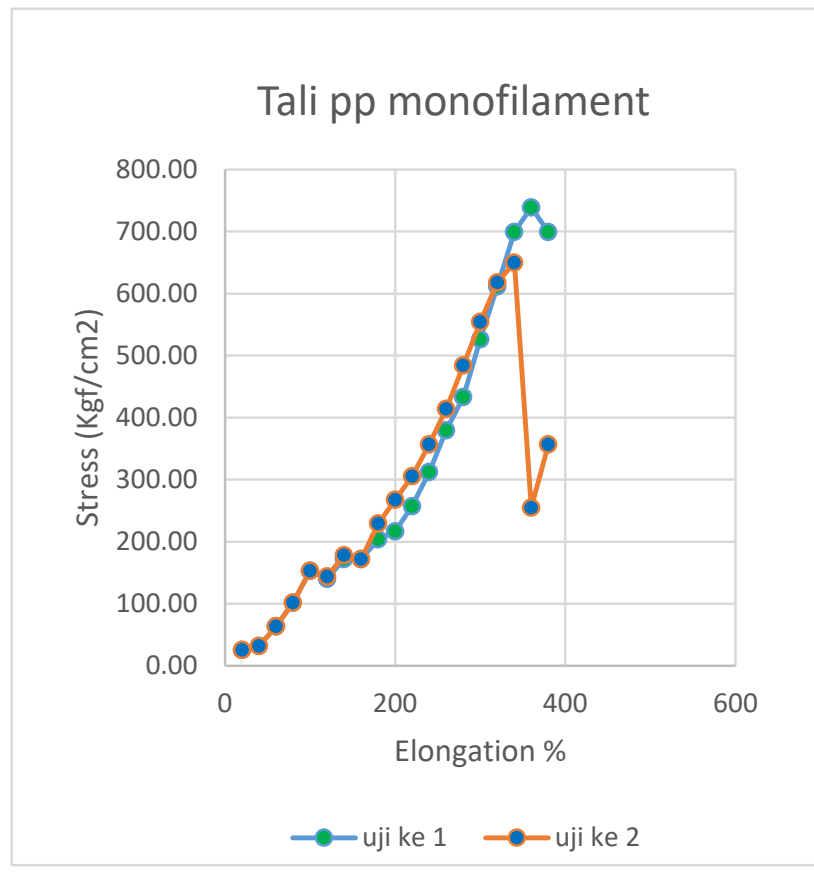

Gambar 6 Grafik Stress - Strain Tali PP Monofilament

Pada data grafik di atas dapat dipaparkan dimana pada pengujian tali polypropylene monofilament didapatkan hasil pada pengujian pertama terlihat pada saat elongation mencapai $360 \%$ nilai Ultimate Tensile Stress (UTS) mencapai 738,85 $\mathrm{kgf} / \mathrm{cm}^{2}$. Sedangkan pada pengujian yang ke dua di saat elongation mencapai nilai $340 \%$ di dapatkan nilai Ultimate Tensile Stress (UTS) sebesar $649,48 \mathrm{kgf} / \mathrm{cm}^{2}$. Sehingga didapatkan nilai rata rata UTS sebesar $694,165 \mathrm{kgf} / \mathrm{cm}^{2}$ dari nilai dua kali pengujian yang dilakukan.

\section{Grafik Tegangan - Tegangan Tali PP Multifilament}

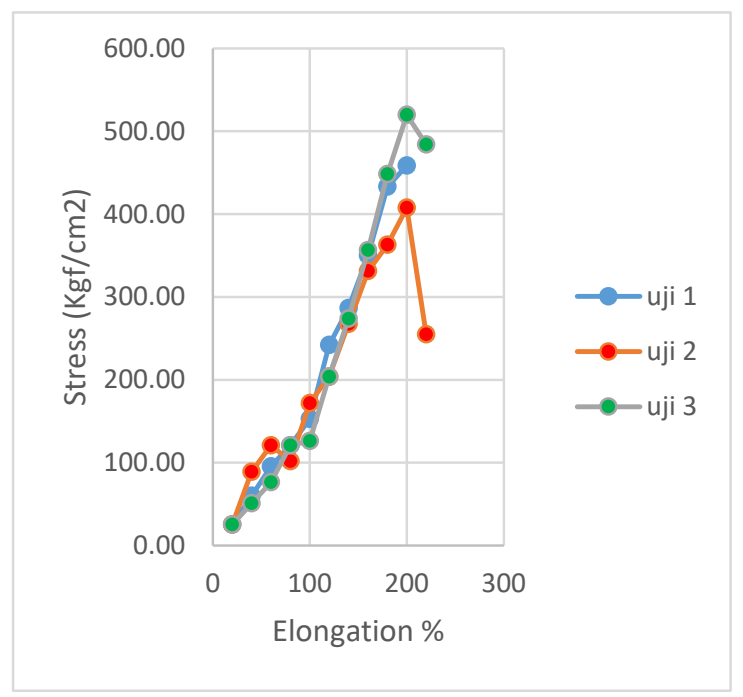

Gambar 7 Grafik Stress - Strain Tali PP Multifilament

Pada gambar grafik 6 dipaparkan di mana pada pengujian tali poplypropylene multifilant didapatkan hasil pada pengujian pertama nilai ultimate tensile stress (UTS) sebesar 458,69 $\mathrm{kgf} / \mathrm{cm}^{2}$ dengan elongation mencapai $200 \%$. Sedangkan pada pengujian ke dua nilai ultimate tensile stress (UTS) lebih rendah dari pengujian pertama yang bernilai $407,64 \mathrm{kgf} / \mathrm{cm}^{2}$ pada elongation $200 \%$. Pengujian ke tiga meiliki nilai ultimate tensile stress (UTS) yang paling tinggi yang bernilai sebesar $519,75 \mathrm{kgf} / \mathrm{cm}^{2}$ dengan elongation yang sama dari sebelumnya sebesar $200 \%$. Maka diperoleh nilai rata - rata dari tiga pengujian yang dilakukan pada tali polypropylene multifilament sebesar $462,02 \mathrm{kgf} / \mathrm{cm}^{2}$.

\section{Grafik Tengangan - Regangan Tali Nylon}

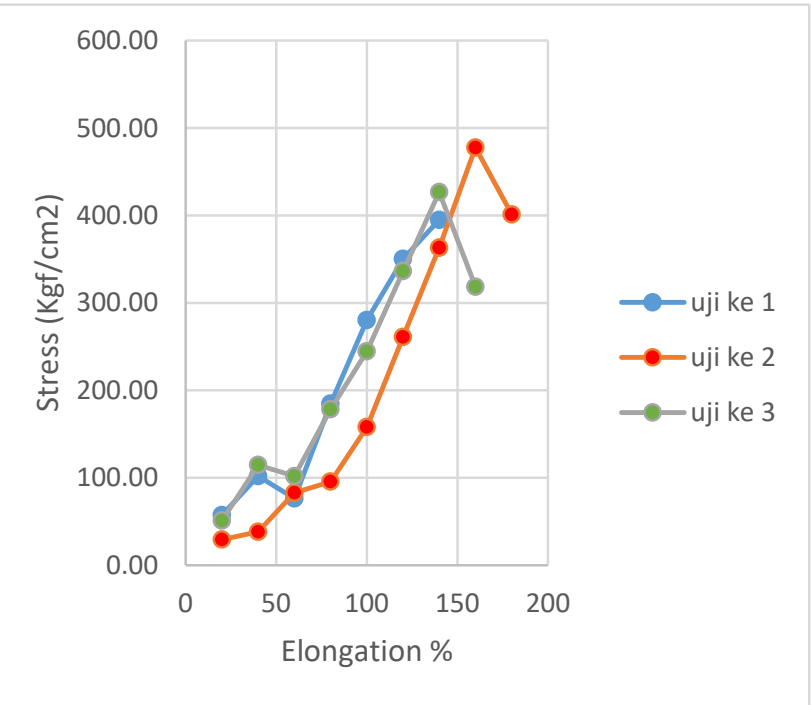

Gambar 8 Grafik Stress - Strain Tali Nylon 
Pada grafik di atas dipaparkan dimana pada pengujian tali nylon di peroleh suatu hasil data di mana dilakukan proses tiga kali uji, yang pada pengujian pertama nilai Ultimate Tensile Stress (UTS) sebesar 394,90 $\frac{\mathrm{kgf}^{2}}{\mathrm{~cm}}$ dengan elongation mencapai $140 \%$. Untuk pengujian ke dua nilai UTS di peroleh sebesar $477,71 \frac{\mathrm{kgf}^{2}}{\mathrm{~cm}}$ dengan elongation sebesar $160 \%$. Lalu pada pengujian ke tiga nilai UTS sebesar $426,75 \frac{\mathrm{kgf}^{2}}{\mathrm{~cm}}$ dengan nilai elongation sebesar $140 \%$. Maka di dapatkan nilai rata - rata dari ke tiga pengujian yang di lakukan pada tali nylon sebesar $433,12 \frac{\mathrm{kgf}^{2}}{\mathrm{~cm}}$.

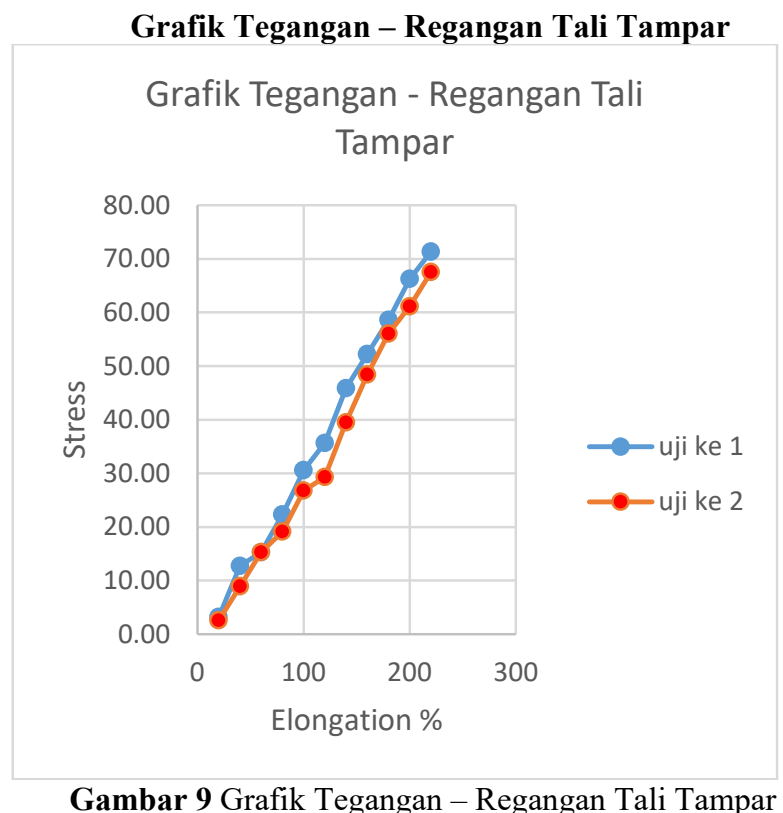

Pada grafik di atas di paparkan di mana pada pengujian Tali Tampar diperoleh suatu hasil data yang mana didapatkan melalui 2 kali pengujain, Pada pengujian ke-1 nilai UTS (Ultimate Tenssile Stress) sebesar $71,34 \mathrm{kgf} / \mathrm{cm}^{2}$ dengan elongation mencapai $220 \%$. Untuk pengujian ke-2 didapatkan nilai Ultimate Tensile Stress (UTS) sebesar $67,52 \mathrm{kgf} / \mathrm{cm}^{2}$ dengan elongation mencapai $220 \%$. Maka dari itu didapatkan nilai rata - rata UTS sebesar $69,43 \mathrm{kgf} / \mathrm{cm}^{2}$.

\section{Perhitungan Nilai Modulus Eslastisitas}

Pada sub ini akan membahas tentang perhitungan nilai modulus dari tiap masing - masing spesimen uji yang mana akan di jabarkan lebih luas di bawah ini.

Perhitungan Modulus Elastisitas Tali PP Monofilament

- Pengujian ke 1

Diketahui :

$$
\begin{array}{ll}
- & \mathrm{X} 1=100 \\
- & \mathrm{X} 2=300 \\
- & \mathrm{Y} 1=152,87 \\
- & \mathrm{Y} 2=526,11
\end{array}
$$

Perhitungan modulus elastisitas:

$$
\mathrm{E}=\frac{\Delta Y}{\Delta X}=\frac{526,11-152,87}{300-100}=1,866 \mathrm{kgf} / \mathrm{cm}^{2}
$$

- $\quad$ Pengujian ke 2

Diketahui :

$$
\begin{array}{ll}
- & \mathrm{X} 1=100 \\
- & \mathrm{X} 2=300 \\
- & \mathrm{Y} 1=152,37 \\
- & \mathrm{Y} 2=554,14
\end{array}
$$

Perhitungan modulus elastisitas:

$$
\mathrm{E}=\frac{\Delta Y}{\Delta X}=\frac{554,14-152,87}{300-100}=2,006 \mathrm{kgf} / \mathrm{cm}^{2}
$$

Perhitungan Modulus Elastisitas Tali PP Multifilament

$$
\text { - } \quad \text { Pengujian ke } 1
$$

Diketahui :

$$
\begin{array}{ll}
- & \mathrm{X} 1=60 \\
- & \mathrm{X} 2=180 \\
- & \mathrm{Y} 1=95,54 \\
- & \mathrm{Y} 2=433,12
\end{array}
$$

Perhitungan modulus elastisitas:

$$
\mathrm{E}=\frac{\Delta Y}{\Delta X}=\frac{433,12-95,54}{180-60}=2,813 \mathrm{kgf} / \mathrm{cm}^{2}
$$

Diketahui :

$$
\begin{array}{ll}
- & \mathrm{X} 1=60 \\
- & \mathrm{X} 2=180 \\
- & \mathrm{Y} 1=121,02 \\
- & \mathrm{Y} 2=363,06
\end{array}
$$

Perhitungan modulus elastisitas:

$$
\mathrm{E}=\frac{\Delta Y}{\Delta X}=\frac{363,06-121,02}{180-60}=2,01 \mathrm{kgf} / \mathrm{cm}^{2}
$$

Diketahui :

$$
\begin{array}{ll}
- & \mathrm{X} 1=60 \\
- & \mathrm{X} 2=180 \\
- & \mathrm{Y} 1=76,43 \\
- & \mathrm{Y} 2=448,41
\end{array}
$$

Perhitungan modulus elastisitas:

$\mathrm{E}=\frac{\Delta Y}{\Delta X}=\frac{448,41-76,43}{180-60}=3,01 \frac{\mathrm{kgf}^{2}}{\mathrm{~cm}}$

\section{Perhhitungan Modulus Elastisitas Tali Nylon}

- $\quad$ Pengujian ke 1

Diketahui :

$$
\begin{array}{ll}
- & X 1=60 \\
- & X 2=120 \\
- & Y 1=76,43 \\
- & Y 2=350,32
\end{array}
$$

Perhitungan modulus elastisitas:

$\mathrm{E}=\frac{\Delta Y}{\Delta X}=\frac{350,52-76,43}{120-60}=4,564 \mathrm{kgf} / \mathrm{cm}^{2}$

Diketahui :

$$
\begin{array}{ll}
- & \mathrm{X} 1=60 \\
- & \mathrm{X} 2=140 \\
- & \mathrm{Y} 1=82,80 \\
- & \mathrm{Y} 2=363,06
\end{array}
$$

Perhitungan modulus elastisitas:

$\mathrm{E}=\frac{\Delta Y}{\Delta X}=\frac{363,06-82,80}{140-60}=3,503 \mathrm{kgf} / \mathrm{cm}^{2}$ 
Diketahui :

$$
\begin{array}{ll}
- & X 1=60 \\
- & X 2=120 \\
- & Y 1=101,91 \\
- & Y 2=336,30
\end{array}
$$

Perhitungan modulus elastisitas:

$\mathrm{E}=\frac{\Delta Y}{\Delta X}=\frac{336,31-101,91}{120-60}=3,906 \mathrm{kgf} / \mathrm{cm}^{2}$

\section{Perhitungan Modulus Elastisitas Tali Tampar}

- Pengujian ke 1

Diketahui :

$$
\begin{array}{ll}
- & X 1=40 \\
- & X 2=200 \\
- & Y 1=12,74 \\
- & Y 2=66,24
\end{array}
$$

Perhitungan modulus elastisitas:

$$
\mathrm{E}=\frac{\Delta Y}{\Delta X}=\frac{66,24-12,74}{200-40}=0,3343 \mathrm{kgf} / \mathrm{cm}^{2}
$$

- Pengujian ke 2

Diketahui :

$$
\begin{array}{ll}
- & \mathrm{X} 1=40 \\
- & \mathrm{X} 2=200 \\
- & \mathrm{Y} 1=8,92 \\
- & \mathrm{Y} 2=61,15
\end{array}
$$

Perhitungan modulus elastisitas:

$$
\mathrm{E}=\frac{\Delta Y}{\Delta X}=\frac{61,15-8,92}{200-40}=0,3264 \mathrm{kgf} / \mathrm{cm}^{2}
$$

Studi Kritis Perbandingan Kekuatan Ke-3 Jenis Spesimen Dari penelitian yang sudah dilakukan baik secara pengujian maupun perhitungan dengan beberapa rumus yang ada. Maka didapatkan berbagai perbandingan dari ke tiga jenis specimen, dimana:

- Dari proses pengujian dengan menggunakan empat specimen tali, nilai Stress tertinggi diperoleh pada tali Polypropylene monofilament dengan nilai stress sebesar 602,17 kgf dengan elongation 382,14\%. Diikuti dengan tali Polypropylene Multifilament dengan nilai stress sebesar $422 \mathrm{kgf}$ dengan elongation 220\%. Dan tali Nylon dengan nilai Stress sebesar 405,5 $\mathrm{kgf}$ dengan elongation sebesar $178 \%$.

- Setelah hasil didapatkan dari proses pengujian tarik, berikutnya akan dilakukan perbandingan nilai perhitungan dengan menggunakan persamaan. Di dapatkan nilai stress tertinggi diperoleh pada Jenis tali polypropylene monofilament dengan nilai stress sebesar $738,85 \mathrm{kgf}$ dengan elongation sebesar 360\%. Diikuti dengan tali polypropylene multifilament dengan nilai stress $519,75 \mathrm{kgf}$ dengan elongation sebesar $200 \%$. Dan tali Nylon dengan nilai stress sebesar 477,71 $\mathrm{kgf}$ dengan nilai elongation sebesar $160 \%$

- Perbandingan ke tiga jenis tali terhadap modulus elastisitas diperoleh dari hasil perumusan dengan menggunakan persamaan, dengan nilai modulus elastisitas tertinggi diperoleh pada tali Nylon sebesar $0,3485 \mathrm{kgf} / \mathrm{cm}^{2}$. Diikuti dengan tali polypropylene multifilament dengan modulus elastisitas sebesar 0,237 $\mathrm{kgf} / \mathrm{cm}^{2}$. Dan berikutnya tali polypropylene monofilament dengan nilai modulus elastisitas sebesar $0,1536 \mathrm{kgf} / \mathrm{cm}^{2}$.

\section{KESIMPULAN}

Dari hasil penelitian yang telah dilakukan maka di dapatkan beberapa kesimpulan sebagai berikut:

1. Dari pengujian tarik yang telah di lakukan, nilai UTS (Ultimate Tensille Stress) tertinggi di dapatkan pada spesimen tali polypropylene monofilament dengan nilai stress sebesar 602, $17 \mathrm{kgf}$ dengan elongation 382,14\%.

2. Data nilai perhitungan stress tertinggi juga diperoleh oleh specimen tali Polypropylene monofilament dengan nilai $738,85 \mathrm{kgf} / \mathrm{cm}^{2}$ pada elongation $\mathrm{ke} 360 \%$.

3. Nilai modulus elastisitas tertinggi diperoleh oleh tali Nylon dengan nilai modulus elastisitas sebesar 4,564 kgf $/ \mathrm{cm}^{2}$. Hal ini menunjukan bahwa modulus elastisitas berbanding terbalik dengan nilai stress yang mana tadinya nilai stress tali nylon yang paling rendah dari spesimen yang lain namun memiliki nilai modulus elastisitas yang paling tinggi di antara specimen yang lain nya. Sehingga rekomendasi terbaik penggunaan nylon untuk tali pada alat ukur torsi pompa pada laboratorium fluida Universitas Muhammadiyah Sidoarjo.

\section{UCAPAN TERIMA KASIH}

Di sini penulis ingin mengucapkan terimakasih kepada semua pihak yang telah membantu proses penelitian ini, teman-teman tim peneliti, dosen pembimbing yang banyak memberikan dukungan, saran dan masukan yang membangun dan juga labolatorim Teknik Mesin Universitas Muhammadiyah Sidoarjo yang telah menyediakan beberapa fasilitas penelitian, dan juga tak lupa terimakasih kepada Balai Pengembangan Industri Persepatuan Indonesia (BPIPI) Sidoarjo yang telah menyediakan alat pengujian sehingga penelitian ini dapat terselesaikan.

\section{REFERENSI}

[1] A. F. Silaen, "Analisa Karakteristik Pompa Sentritugal Rangakaian Single, Serie Dan Paralel. Telematik," J. rekayasa pangan dan Pertan., vol. 2, no. 2, 2011.

[2] R. Y. Pradhana and E. Widodo, "Analisa Pengaruh Variasi Diameter Pipa Tekan Pvc Pada Pompa Aksial Untuk Kecepatan Gaya Dorong Air," R E.M. (Rekayasa Energi Manufaktur) J., vol. 2, no. 1, pp. 37-43, 2017.

[3] Edi Widodo; Gagah Deffi Priyambudi, "REKAYASA SLIDING SEAT PADA POMPA OBSERVASI UNTUK EFEKTIFITAS LABORATORIUM," TURBO J. Tek. Mesin Univ. Muhammadiyah Metro, vol. 7, no. 1, pp. 65-73, 2018.

[4] E. W. R. Y. Pradana, "Analysis of pipe diameter variation in axial pumps for reducing head loss," in 20171 st International Conference on Engineering and Applied Technology (ICEAT), 2018, pp. 1-8.

[5] I. N. Gusniar, "OPTIMALISASI SISTEM PERAWATAN POMPA SENTRIFUGAL DI UNIT UTILITY PT.ABC," $J$. Ilm. SOLUSI, vol. 1, no. 1, 2014.

[6] F. Ansori and E. Widodo, "Analysis on Centrifugal Pump Performance in Single, Serial, and Parallel," JEMMME (Journal Energy, Mech. Mater. Manuf. Eng., vol. 3, no. 2, pp. 79-86, 2018.

[7] G. Suwoto, "Kaji Eksperimental Kinerja Turbin Air Hasil 
Modifikasi Pompa Sentrifugal untuk Pembangkit Listrik Tenaga Mikrohidro," in SNST ke-3 Tahun 2012, 2004, pp. 60-64.

[8] S. Abouda, F. Nollet, A. Chaari, N. Essounbouli, and Y. Koubaa, "Direct Torque Control - DTC of Induction Motor Used for Piloting a Centrifugal Pump Supplied by a Photovoltaic Generator," Int. J. Electr. Comput. Energ. Electron. Commun. Eng., vol. 7, no. No : 8, pp. 1110-1115, 2013.

[9] U. Klinge K. Junge M. Stumpf A. P. Öttinger B. Klosterhalfen, "Functional and morphological evaluation of a low-weight, monofilament polypropylene mesh for hernia repair," J. Biomed. Mater. Res., vol. 63, no. 2, 2002.

[10] Novrizal, "VISIBILITAS TALI MULTIFILAMEN UNTUK BAHAN ALAT PENANGKAPAN IKAN PADA KEDALAMAN PERAIRAN YANG BERBEDA," Berk. Perikan. Terubuk, vol. 42, no. 1, 2014.

[11] and C. C. C. Charles Scott, Dan Wu, Chia-Chi Ho, "LiquidCore Capsules via Interfacial Polymerization: A Free-Radical Analogy of the Nylon Rope Trick," J. Am. Chem. Soc., vol. 127, no. $12,2005$.

[12] E. H. Purwono and B. Yatnawijaya, "Kekuatan Bahan Tali Tampar," Rev. Urban. Archit. Stud., vol. 11, no. 1, pp. 102112, 2013. 